\title{
Caracterização do vinagre artesanal produzido com casca de maçã
}

\author{
Characterization of artisanal vinegar produced with apple peel \\ Caracterización del vinagre artesanal elaborado con piel de manzana
}

Recebido: 04/07/2021 | Revisado: 08/07/2021 | Aceito: 08/07/2021 | Publicado: 19/07/2021

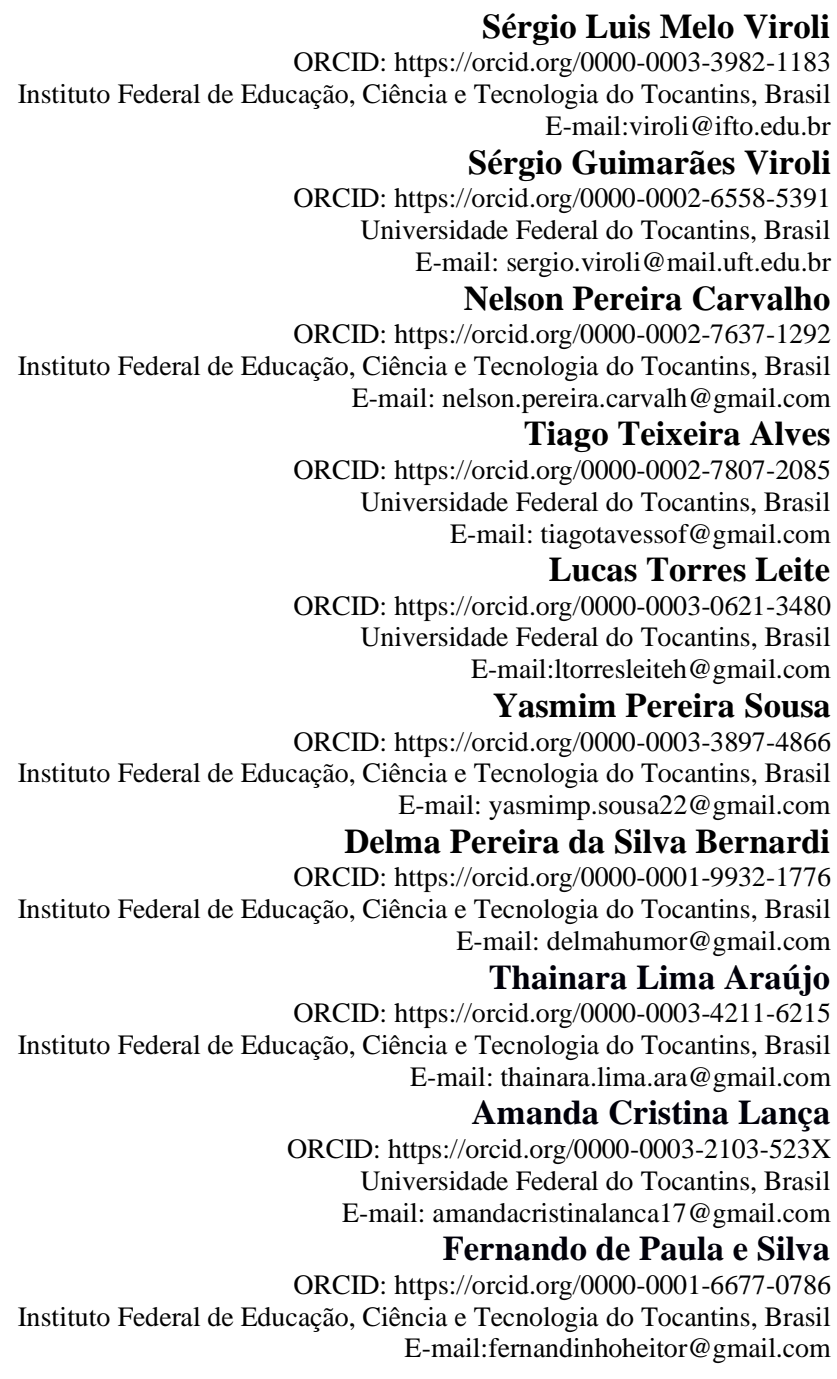

\section{Resumo}

O vinagre pode produzido de qualquer fonte de carboidrato, frutas, substrato amiláceo ou açucarado através de duas fermentações sucessivas, a alcoólica realizada por meio de leveduras e a acética por bactéria. A produção de vinagres de frutas como forma de aproveitamento de subprodutos de frutas é uma opção amplamente utilizada pela indústria alimentícia. A presente pesquisa produziu e caracterizou um vinagre elaborado a partir das cascas de maçã. O processo de fermentação utilizou a casca de maçã com meio de cultura, maceração através da solução hidroalcóolica a $10 \%$ em temperatura entre $27 \pm 1^{\circ} \mathrm{C}$ com irrigação 3 (três) vezes ao dia, sem aeração por 12 dias. Foram realizadas determinações físico-químicas de acidez volátil, $\mathrm{pH}$ e teor de álcool a $20^{\circ} \mathrm{C}$. A análise de variância ANOVA e o teste de Tukey a 5\% identificaram diferença entre o vinagre de maçã comercial e o artesanal produzido com casca de maçã. $\mathrm{O}$ vinagre produzido com casca de maçã apresentou resultado dentro do estabelecido pela legislação brasileira. A relação entre as variáveis físico-químicas e os vinagres artesanal e industrial foram estudadas pela Análise de Componentes Principais (PCA). Obteve-se, com 2 componentes, mais de 99,98\% da variabilidade dos explicados. O vinagre produzido com casca de maçã possui os parâmetros físico químico acidez e teor alcoólico dentro do preconizado pela legislação, características físico-químicas semelhantes aos produzidos industrialmente e adequado para o consumo como vinagres comerciais.

Palavras-chave: Agricultura familiar; Fruta; Reuso; Resíduos agroindustriais. 


\begin{abstract}
Vinegar can be produced from any source of carbohydrate, fruit, starchy or sugary substrate through two successive fermentations, the alcoholic one carried out by yeasts and the acetic one by bacteria. The production of fruit vinegar as a way to use fruit by-products is an option widely used by the food industry. The present research produced and characterized a vinegar made from apple peel. The fermentation process used apple peel with culture medium, maceration through a $10 \%$ hydroalcoholic solution at a temperature between $27 \pm 1^{\circ} \mathrm{C}$ with irrigation 3 (three) times a day, without aeration for 12 days. Physicochemical determinations of volatile acidity, $\mathrm{pH}$ and alcohol content at 20 ${ }^{\circ} \mathrm{C}$ were carried out. Analysis of variance ANOVA and Tukey's test at 5\% identified differences between commercial apple cider vinegar and artisanal apple peel vinegar. The vinegar produced with apple peel presented results within the established by Brazilian legislation. The relationship between physicochemical variables and artisanal and industrial vinegars were studied by Principal Component Analysis (PCA). With 2 components, more than 99.98\% of the explained variability was obtained. Vinegar produced with apple peel has the physical chemical parameters, acidity and alcohol content within the recommended by legislation, physical-chemical characteristics similar to those produced industrially and suitable for consumption as commercial vinegars.
\end{abstract}

Keywords: Family farming; Fruit; Reuse; Agro-industrial waste.

\title{
Resumen
}

El vinagre se puede producir a partir de cualquier fuente de carbohidratos, frutas, sustrato almidonado o azucarado a través de dos fermentaciones sucesivas, alcohólica por levadura y acética por bacterias. La elaboración de vinagre de frutas como forma de aprovechamiento de subproductos de frutas es una opción muy utilizada por la industria alimentaria. La presente investigación produjo y caracterizó un vinagre elaborado a partir de cáscara de manzana. El proceso de fermentación utilizó piel de manzana con medio de cultivo, maceración en solución hidroalcohólica al $10 \%$ a una temperatura entre $27 \pm 1^{\circ} \mathrm{C}$ con riego 3 (tres) veces al día, sin aireación durante 12 días. Se realizaron determinaciones fisicoquímicas de acidez volátil, $\mathrm{pH}$ y contenido de alcohol a $20^{\circ} \mathrm{C}$. El análisis de varianza ANOVA y la prueba de Tukey al 5\% identificaron diferencias entre el vinagre de sidra de manzana comercial y el vinagre de cáscara de manzana hecho a mano. El vinagre elaborado con piel de manzana presentó resultados dentro de lo establecido por la legislación brasileña. La relación entre las variables físico-químicas y los vinagres artesanales e industriales se estudió mediante el Análisis de Componentes Principales (PCA). Con 2 componentes se obtuvo más del 99,98\% de la variabilidad explicada. El vinagre elaborado con piel de manzana tiene parámetros físico-químicos, acidez y contenido alcohólico dentro de los recomendados por la ley, características físico-químicas similares a las producidas industrialmente y aptas para el consumo como vinagres comerciales.

Palabras clave: Agricultura familiar; Fruta; Reutilizar; Residuos agroindustriales.

\section{Introdução}

Todos os anos, grandes quantidades de frutas produzidas são descartadas, pois o excesso não pode ser consumido pela indústria porque os frutos são considerados de segunda ou terceira categoria de qualidade e não são absorvidas pelo mercado consumidor por falta de especificação (Quintana, Castro \& Guerrero, 2021). Segundo a Food and Agriculture Organization [FAO] (2019), 21,6\% das frutas produzidas no mundo são desperdiçadas a partir da colheita até a sua distribuição. A fruta é recusada por apresentar imperfeições, injúrias ou tamanho inadequado, mesmo que o fruto seja perfeitamente comestível. Embora existam alternativas como a produção de polpa de frutas, sucos, ou mesmo geleias, grandes quantidades ainda são desperdiçadas, pois as frutas são eliminadas como resíduo e deixada no campo até se decomporem. (Quintana, Castro \& Guerrero, 2021). Essas ações geram consequências ambientais e econômicas, pois o impacto ambiental gerado pelos resíduos da fruticultura e o aumento do produto podem estar relacionados a superprodução de frutas. Alternativas que utilizem esse excedente e reduza o impacto gerado na indústria de frutas são extremamente valiosos. Uma alternativa para a utilizações dos resíduos da fruticultura é a elaboração de vinagres macerados com diferentes partes da fruta (Perestrelo et al. 2018, Bruna-Maynou et al, 2020).

O vinagre pode ser produzido de qualquer fonte de carboidrato, frutas, substrato amiláceo ou açucarado através de duas fermentações sucessivas, a alcoólica realizada por meio de leveduras e a acética por bactéria (Viana et al, 2017). A produção de vinagres de frutas como forma de aproveitamento integral ou subprodutos de frutas é uma opção amplamente utilizada pela indústria alimentícia. Os frutos excedentes ou que apresentam falta de tamanho especificado para o mercado consumidor, podem ser aproveitados sem comprometer a qualidade do produto final. A natureza acética dos vinagres e o 
impacto nas propriedades organolépticas do produto final permite que quase qualquer tipo de fruta seja utilizada para elaboração de vinagre (Quintana, Castro \& Guerrero, 2021).

A maçã (Malus spp.) é provavelmente a fruta mais antiga conhecida pelo homem e preferida por milhões de pessoas em todo o mundo (Viana et al, 2017). Ela é uma das frutas mais cultivadas e consumidas no mundo, possuindo mais de 2,5 mil espécies existentes. Segundo o Serviço Brasileiro de Apoio às Micro e Pequenas Empresas [SEBRAE] (2020), as variedades de maçãs mais cultivadas no Brasil são: gala, golden, delicius e Fuji. O Brasil está entre os 12 maiores produtores de maçã do mundo (Bueno et al, 2021). No Brasil, em 2020, foram produzidas 980 mil toneladas de maçã. Em 2021 a previsão é de 1,3 milhão de toneladas. Em Palmas - RS, para a safra de 2021 a previsão é de que sejam colhidas 13 mil toneladas de maçã. Desse total, cerca de $55 \%$ são da Gala, 40 \% Fuji e 5\% Eva (ABRAFRUTAS, 2021). A produção de vinagre podem ser uma boa solução para o desperdício durante a colheita, alta produtividade por árvore, curta vida de prateleira do frutas frescas e a falta de uso dessas frutas no processamento produtos (Viana et al.2017).

O vinagre de maçã é rico em nutrientes e possui sabor característico, sendo produzido a partir de maçãs ou de seus subprodutos por processos fermentativos alcoólico e acético. (Štornik et al. 2016, Liu et al. 2019). Além disso, o vinagre de maçã é abundante em aminoácidos, ésteres e outros nutrientes (Chen et al. 2017). Ele tem função antioxidante e uma variedade de substâncias que têm efeitos benéficos para os tratamentos de beleza e imunidade (Wang et al. 2017, Xie et al. 2017, Wu et al. 2017). Nos últimos anos, as pesquisas têm sido focadas no sabor e nas substâncias funcionais do vinagre de frutas pois, aumentou o interesse do consumidor em usar vinagre de frutas para se manter saudável e prevenção contra doenças. Os componentes do aroma são indicadores importantes da qualidade do vinagre de maçã. O sabor característico é determinado pelo tipo, quantidade e interações entre os componentes (Liu et al. 2019). O vinagre de maçã possui propriedades medicinais e benefícios gerais para a saúde. Contém minerais e vitaminas A, C, E, várias formas diferentes da vitamina B, beta caroteno e flavonoide, pois essas substâncias são necessárias para o funcionamento celular. Ele é antioxidante, antiglicêmico, antihipertensivo, antibacteriano e antifúngico (Budak, et al, 2014). O vinagre de maçã pode colaborar com benefícios saudáveis tais como, perda de peso, a redução dos níveis de glicose no sangue em pessoas com diabetes tipo 2 mellitus, ou diminuição do risco de doenças cardíacas (Song et al., 2019, Launholt, Kristiansen \& Hjorth, 2020).

Portanto, este trabalho aborda a produção e caracterização do vinagre elaborado com casca de maçã através da maceração em solução hidroalcóolica a 10\% em reator de polietileno tereftalato.

\section{Metodologia}

O estudo realizado utilizou o método quantitativo para obtenção de dados uma vez que a utilização, dos números e cálculos matemáticos, viabiliza a avaliação da análise estatística (Pereira, et al, 2018). A pesquisa quantitativa utiliza a estatística para verificação da hipótese.

\subsection{Construção do reator de polietileno tereftalato}

Durante o mês de maio do ano de 2020, foram adquiridas garrafas PET em bares, lanchonetes e restaurantes do Município de Paraíso do Tocantins. As garrafas foram utilizadas na construção de um reator para a produção de vinagre com cascas de maçã. O reator foi desenvolvido de acordo com um fluxograma (Figura 1), aplicando a metodologia utilizada por Santos et al (2008). 
Figura 1. Fluxograma de construção do reator (garrafa pet) para fermentação acética de cascas de frutas.

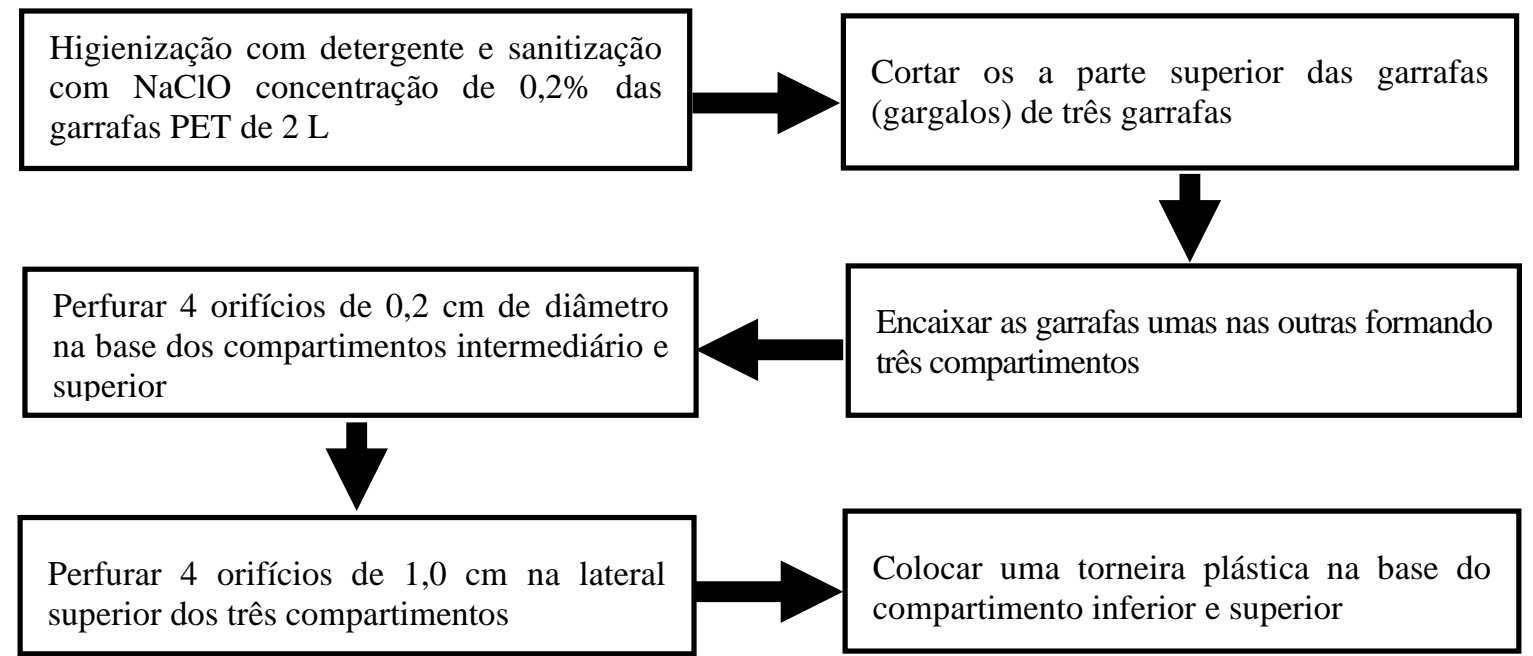

Fonte: Santos et al. (2008)

O reator foi utilizado no processo da maceração das cascas de maçã para produção de vinagre através do processo lento de fermentação.

\subsection{Produção do vinagre com cascas de maçã}

O experimento cientifico foi realizado na unidade de beneficiamento e hortaliças do Instituto Federal de Educação do Tocantins - IFTO: campus Paraíso. As maçãs gala, utilizados para a produção do vinagre, foram adquiridos em supermercados e frutarias do Município de Paraíso do Tocantins. Os frutos foram adquiridos de acordo com o estágio de maturação representado pela Figura 2.

Figura 2. Estagio de maturação das cascas das maçãs utilizadas na fabricação do vinagre

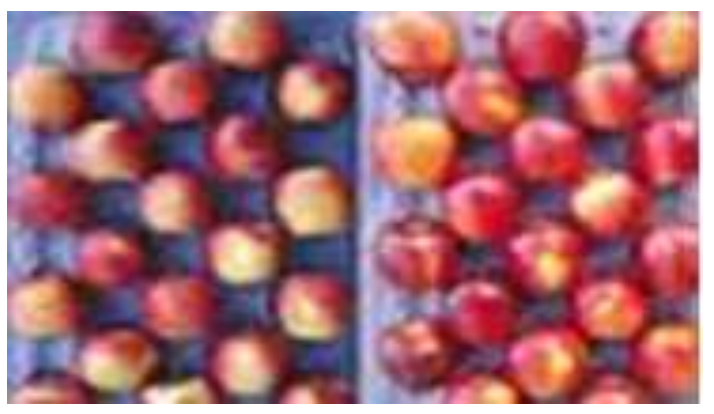

Fonte: Betinelli et al. (2017)

O processo fermentativo foi desenvolvido utilizando casca de maçã, com meio de cultura, maceradas com solução hidroalcóolica a $10 \%$ em temperatura entre $27 \pm 1{ }^{\circ} \mathrm{C}$, com irrigação 3 (três) vezes ao dia por 12 dias sem aeração (Santos et al, 2008). Após o processo fermentativo, o vinagre produzido pelo processo de fermentação lenta foi filtrado, armazenado e esterilizado em recipiente de vidro.

\subsection{Analises físico químicas}

As determinações físico-químicas usadas nas análises de acidez volátil (g.mL $\left.\mathrm{mL}^{-1}\right)$, potencial de hidrogênio $\mathrm{pH}$ e teor de álcool a $20^{\circ} \mathrm{C}\left(\% \mathrm{vv}^{-1}\right)$ foram realizadas em triplicata e seguiram o procedimento metodológico do Instituto Adolfo Lutz [IAL, $2008]$. 


\subsection{Analises dos dados}

Os resultados das análises físico-químicas, de acidez, potencial de hidrogênio e teor de álcool foram submetidos à análise de variância ANOVA. Para verificar se houve diferença significativa entre os resultados foi aplicada ANOVA e entre as médias das variáveis respostas o teste de Tukey ao nível de 5\% de significância. A análise de variância e teste de Tukey foram realizados no programa Sisvar versão 5.6 (Ferreira, 2019).

A Análise de Componentes Principais (ACP) analisou os dados em que os tratamentos estão relacionados por variáveis resposta inter-relacionadas, onde o objetivo foi agrupar as variáveis físico-químicas de acordo com a similaridade. A Análise de Componentes Principais (ACP) foi utilizada para agrupar as variáveis físicas e químicas de acordo com a similaridade. A ACP foi realizada em dados padronizados para evitar o efeito de diferentes níveis de magnitude das variáveis de resposta. A padronização dos dados para cada variável resposta foi feita subtraindo cada valor pela sua média dividida pelo erro padrão. A análise do ACP foi realizada com o software PAST (Hommer; Harper \& Ryan, 2001).

\section{Resultados e Discussão}

A Tabela 1 apresenta o resumo da análise de variância ANOVA demostrando a contagem, soma, média variâncias entre os grupos.

Tabela 1. Resumo da análise de variância.

\begin{tabular}{ccccc}
\hline Grupo & Contagem & Soma & Média & Variância \\
\hline Coluna 1 & 6 & 26,21 & 4,368333 & 0,045697 \\
Coluna 2 & 6 & 18,09 & 3,015 & 0,01411 \\
Coluna 3 & 6 & 0,62 & 0,103333 & 0,012827 \\
\hline
\end{tabular}

Fonte: Autores (2021).

A análise de variância ANOVA admite comparações de grupos independentes, buscando a verificação da veracidade da hipótese nula $\left(\mathrm{H}_{0}\right)$ pressupondo se que não existe diferença entre os efeitos estudados ou da hipótese alternativa $\left(\mathrm{H}_{1}\right)$ onde há diferenças significativas entre os efeitos estudado pelo pesquisador (Moore 2 Notz \& Flinger, 2017; Assis et al, 2020). (Ho é tida como verdadeira até que surja $\left(\mathrm{H}_{1}\right)$ com uma baixa probabilidade de erro (valor $\mathrm{p}$ ).

ATabela 2 apresenta a análise de variância ANOVA demostrando a soma dos quadrados (SQ), grau de liberdade(gl), média dos quadrados (MQ) teste de significância $(\mathrm{F})$, probabilidade $(\mathrm{p})$

Tabela 2. Análise de variância

\begin{tabular}{ccccccc}
\hline Fonte da variação & SQ & gl & MQ & F & valor-p & F crítico \\
\hline Entre grupos & 56,99908 & 2 & 28,49954 & 1177,126 & $3,24 \mathrm{E}-17$ & 3,68232 \\
Dentro dos grupos & 0,363167 & 15 & 0,024211 & & & \\
Total & 57,36224 & 17 & & & & \\
\hline
\end{tabular}

Fonte: Autores (2021).

Ao nível de 5\% de significância, tabela 2, o valor de p é 3,23 x $10^{-17}(\mathrm{p}<0,05)$ indicando que $\left(\mathrm{H}_{0}\right)$ foi rejeita e que existem diferenças significativas entre os efeitos estudados que não são ocasionadas pelo acaso. O valor p está relacionado com a probabilidade de observação do valor estatístico do teste ser maior ou igual ao valor encontrado. Convencionalmente, adota se o valor de corte para recusar $\mathrm{H}_{0}$ é igual $5 \%(0,05)$, significando que, quando não há diferença, um valor máximo para a 
estatística de teste é esperado em menos de 5\% das vezes (Ferreira \& Patino, 2015). Admitindo se um valor crítico de p menor ou igual a $5 \%(\mathrm{p} \leq 0,05)$, aceita se um limite de segurança $5 \%$ de erro ou $95 \%$ de certeza. O valor de $\mathrm{p}$ simboliza a probabilidade entre os tratamentos ser ao acaso e não aos fatores que estão sendo estudados. Isso significa que a possibilidade de a diferença entre as médias ser devido ao acaso e não a um efeito dos tratamentos é de 3,23 x $10^{-15} \%$ ou seja, as diferenças entre as médias ocorreram por causa dos tratamentos e não ao acaso tendo $3,23 \times 10^{-15 \%}(\mathrm{p}<0,05)$ de erro.

A Tabela 3 mostra o resultado da ANOVA (teste Tukey a 5\%) das análises físico-químicas dos vinagres artesanal produzido com casca de maçã e o industrializado.

Tabela 3. Característica físico-química do vinagre artesanal produzido com cascas de maçã e industrializado

\begin{tabular}{lccc}
\hline Vinagres & Acidez $\%$ & $\mathrm{pH}$ & Teor Alcoólico \% (v/v) \\
\hline Casca da maçã & $4,56^{\mathrm{B}} \pm 0,01$ & $2,91^{\mathrm{A}} \pm 0,01$ & $0,21^{\mathrm{B}} \pm 0,01$ \\
Comercial de maçã & $4,17^{\mathrm{A}} \pm 0,01$ & $3,12^{\mathrm{B}} \pm 0,01$ & $0,00^{\mathrm{A}} \pm 0,00$ \\
Legislação* & $\geq 4,0\left(\mathrm{~g} \cdot \mathrm{mL}^{-1}\right)$ & ---------- & $\leq 1,0(\% \mathrm{v} / \mathrm{v})$ \\
\hline
\end{tabular}

Médias com letras diferentes na coluna significam que os vinagres diferiram entre si pelo teste de Tukey $(\mathrm{p}<0,05)$.

* Instrução Normativa n ${ }^{\circ}$ 6/2012 do MAPA.

Fonte: Autores (2021).

Os parâmetros físico químicos analisados foram influenciados pelo tipo de matéria-prima e processo de fabricação. $\mathrm{O}$ vinagre produzido artesanalmente com cascas de maçã apresentou diferenças significativas ao nível de $5 \%$ em relação ao vinagre comercial industrializado, indicando a influência da matéria prima e do tipo de processamento na qualidade final do produto. Os resultados obtidos nas análises físico-químicas apresentaram valores de acordo com a Instrução Normativa ${ }^{\circ} 6$, de 3 de abril de 2012 do Ministério da Agricultura, Pecuária e Abastecimento (BRASIL, 2012). O potencial de hidrogênio pH não têm limites especificados na referida legislação.

Os resultados encontrados na tabela 3, estão em concordância com os encontrados por Viroli et al (2019), que produziram e caracterizaram vinagre com casca de maçã, encontram valores para o potencial hidrogeniônico pH 2,57 $\pm 0,02$; acidez $4,86 \% \pm 0,03$ e teor alcoólico $0,23 \% \pm 0,04$. Santos et al. (2008), produzindo vinagre com reaproveitamento de casca de frutas obtiveram valores para $\mathrm{pH} 2,72 \pm 0,04$; acidez 4,54\% $\pm 0,08$ e teor alcoólico $0,25 \% \pm 0,08$. Os resultados encontrados por Ezemba et al (2021), avaliando a produção de vinagre com combinação de maçã verde e vermelha durante 90 dias, para as médias dos valores do $\mathrm{pH} 3,22 \pm 0.21$ e acidez de 1,94 (\%) \pm 0.72 . Hasan et al (2021), encontrou variação de 3,1 a 4 para o pH e 2,0\% a 6,4\% para a acidez em estudo realizado com vinagre de maçã. Os valores encontrados por Ezembra e Hasan discordam dos valores encontrado nesse estudo.

Os baixos valores de acidez volátil encontrados nos vinagre artesanal produzido com casca de maça e vinagre industrializado demostram o controle tecnológico da produção e sanidade da matéria prima, pois teores elevados indicam alterações microbiológicas ( Kang, Há \& Lee, 2020). A acidez volátil corresponde aos ácidos voláteis encontrados no vinagre. $\mathrm{O}$ aumento da acidez, indicam alterações microbiológicas, ocasionadas pela falta de sanidade das frutas, limpeza e higiene dos recipientes e por outros procedimentos inadequados na fabricação e preservação do vinagre (Rizzon et al., 1998; Kang, Há \& Lee, 2020). As propriedades químicas e organolépticas do vinagre estão relacionadas com a matéria prima e o processo de fermentação. Ácido acético, ácido orgânico volátil que identifica os produtos como vinagre, é responsável pelo sabor picante, levantando o odor do vinagre. (Umaru et al, 2015). O vinagre é conhecido por seu gosto ácido. O aroma e sabor de vinagres são influenciados pelas matérias-primas utilizadas, os compostos formados durante o processo e o tipo de fermentação utilizada (Jingjing et al, 2016). A aceitação sensorial do vinagre e influenciada pela acidez, pois o percentual de ácido acético é 
diretamente proporcional à acidez percebida sensorialmente (Marques et al., 2008). O envelhecimento do vinagre permite a morosidade das transformações químicas, transformando resíduos de acetaldeído, etanol, ácido acético e outros, produzindo ésteres e hemi-acetais, de sabores e odores mais agradáveis (Marques et al., 2008).

As mudanças no pH podem ser resultado do processo da fermentação e do aumento da acidez na composição das amostras conforme o período da fermentação. Esta mudança na acidez titulável é gradual e também pode ser atribuída a conversão dos álcoois em ácido acético que é o principal ácido orgânico encontrado em vinagres. Outros ácidos orgânicos podem se formar e também contribuir para o aumento da acidez titulável do vinagre. (Ezemba et al 2021). A acidez e o pH influenciam diretamente as características sensoriais dos vinagres. Em vinagres de maçã com acidez em torno de 5\%, estima-se variações de pH entre 2,46 a 3,18 (White, 1971, Marques et al., 2008).

Rizzon e Miele (1998) estudaram a composição analítica de vinagres brasileiros de vinho tinto e vinho branco, encontraram valores médios para o teor alcoólico de 0,13\% e 0,15\%, respectivamente. Marques, et al. (2010), analisando o teor alcoólico em fermentados acético de maçã, encontraram um valor de $0 \%$ nas amostras analisadas. Possivelmente, a metodologia utilizada pelos autores para determinar o teor de álcool não foi sensível o suficiente para detectar as baixas concentrações de álcool no fermentado acético. A produção teórica do ácido acético a partir do álcool etílico, baseia-se na premissa de que $1 \mathrm{~g}$ de etanol produz 1,304 g de ácido acético (Aquarone \& Zacanaro, 1983, Tessaro et al, 2010). Baseado nesse nessa afirmação, houve maior produção de vinagre com a utilização das cascas de maçã, em virtude da maior quantidade de etanol disponível para ser utilizado como substrato (Tessaro et al, 2010). Segundo White (1971) considera-se eficiente uma conversão de álcool em ácido acético na ordem de 70\%, podendo chegar a uma eficiência de $90 \%$ a $98 \%$.

O processo lento de fabricação (artesanal) produziu vinagre com conteúdo alcoólico maior que o industrial. A restrição do fornecimento de oxigênio utilizado pelas bactérias acéticas na transformação etílica em acética produz alto teor de ácido acético, o que não acontece no processo de fabricação rápida (industrial) de vinagres que utilizam equipamentos específicos para suprimento de oxigênio durante a transformação (Mahamuni \& Gilda, 2020; Marques et al., 2008; García et al, 2009).

A transformação do álcool etílico em ácido acético, por bactérias acéticas, é um processo que requer grandes volumes de oxigênio. Em um fermentador submerso industrial, o rendimento de ácido acético pode ser de até 95-98\% do teor de etanol inicial, e a conversão pode ocorrer dentro de um ou alguns dias (García et al, 2009, Raspor \& Goranovič, 2008). É importante considerar que é desejável que existam pequenas quantidades de álcool residual no vinagre produzido, sendo que isso repercutirá favoravelmente no aroma ou flavor dos vinagres, por formação do buquet, principalmente se houver armazenamento do produto durante alguns meses. Além disso, principalmente em se tratando de armazenamento em longo prazo, o consumo de todo o álcool dos vinagres, favorece o consumo pelas bactérias acéticas de ácido acético dos mesmos, originando produtos de baixa qualidade. A baixa produção de ácido acético pode ocorrer devido à conversão inadequada de etanol em acetaldeído ou indisponibilidade de microrganismos envolvidos no mecanismo de fermentação durante a produção do vinagre (Hazan el al, 2021).

A Tabela 4 apresenta a matriz de correlação entre as variáveis físico químicas consideradas para o modelo de análise das componentes principais. Por meio da matriz de correlação foi possível identificar a relação entre as variáveis. 
Tabela 4. Matriz de correlação entre as variáveis físico-químicas do vinagre

\begin{tabular}{lccc}
\hline & Acidez \% & Potencial hidrogeniônico pH & Teor Alcoólico \% (v/v) \\
\hline Acidez \% & & $1,58 \mathrm{E}-01$ & $4,86 \mathrm{E}-02$ \\
Potencial hidrogeniônico pH & $-0,99675$ & & $1,41 \mathrm{E}-02$ \\
Teor Alcoólico \% (v/v) & 0,9982 & $-0,99903$ & \\
\hline
\end{tabular}

Fonte: Autores (2021).

Segundo Hopkins (2016), as correlações se classificam em: muito baixa $(0,0<\mathrm{r} \leq 0,1)$, baixa $(0,1<\mathrm{r} \leq 0,3)$, Moderada $(0,3<\mathrm{r} \leq 0,5)$, Alta $(0,5<\mathrm{r} \leq 0,7)$, muito alta $(0,7<\mathrm{r} \leq 0,9)$ e extremamente alta $(0,9<\mathrm{r} \leq 1,0)$. A matriz de correlação apresentou correlações extremamente altas entre as variáveis estudadas $\mathrm{r}=0,99$. A correlação entre acidez e teor alcoólicos foi positiva e as correlações entre acidez e potencial hidrogeniônico e teor alcoólico e potencial hidrogeniônico foram negativas.

Pelo emprego da análise de componentes principais identificou-se que o melhor comportamento das variáveis relacionadas produção de vinagre foi aquele composto por duas componentes iniciais, explicando 99,97\% da variância total dos dados (Tabela 5).

Tabela 5. Componentes principais (CP), autovalores (autovalor) e porcentagem da variância explicada

\begin{tabular}{ccc}
\hline PC & Autovalores & \% da variância explicada \\
\hline 1 & 2,98869 & 99,866 \\
2 & 0,0033389 & 0,1113 \\
3 & 0,000673394 & 0,022446 \\
\hline
\end{tabular}

Fonte: Autores (2021).

Com base nos resultados obtidos pelas análises de componentes principais, os respectivos autovalores e porcentagens da variância, demostrando na Tabela 5, indica que dois primeiros PCs (PC1 e PC2) foram responsáveis por 99,98\% da variação total, produção do vinagre, em que o PC1 foi responsável por 99,87\% e o segundo, PC2, por 0,11\% das variações dos dados. A soma de componentes principais I e II ( $\geq 75 \%)$ apresentou adequadamente a variabilidade entre as amostras (Abdi \& Williams, 2010; Fraga et al, 2015).

Tabela 6. descreve os pesos dos componentes principais CP1 e CP2 para as variáveis físico químicas estudadas.

Tabela 6. Pesos das principais componentes para as variáveis analisadas.

\begin{tabular}{ccc}
\hline Variáveis físico químicas & PC 1 & PC 2 \\
\hline Acidez \% & 0,57715 & 0,76997 \\
Potencial hidrogeniônico pH & $-0,57731$ & 0,62037 \\
Teor Alcoólico \% (v/v) & 0,57759 & $-0,14931$ \\
\hline
\end{tabular}

Fonte: Autores (2021)

De acordo com os dados apresentados na Tabela 6, verifica-se que a primeira componente principal (CP1) apresenta maior peso para a variável teor alcoólico e a componente principal (CP2) apresenta maiores pesos nas variáveis acidez volátil e 
potencial hidrogeniônico pH. Observa se que a (CP1) representa uma variável nova que engloba o teor alcoólico e a (CP2) uma outra variável que engloba a acidez volátil e o $\mathrm{pH}$.

O gráfico 1 apresenta as componentes principais (CP1) e (CP2), exibindo os seus respectivos pesos, possibilitando uma visualização dos principais agrupamentos no conjunto de variáveis. A Figura 3, apresenta o gráfico 1 da análise dos principais componentes do vinagre produzido com casca de maçã artesanalmente pelo método lento em comparação ao vinagre industrial produzido pelo método rápido.

Figura 3. Gráfico 1 da análise de componente principal para os vinagres artesanal e indústria.

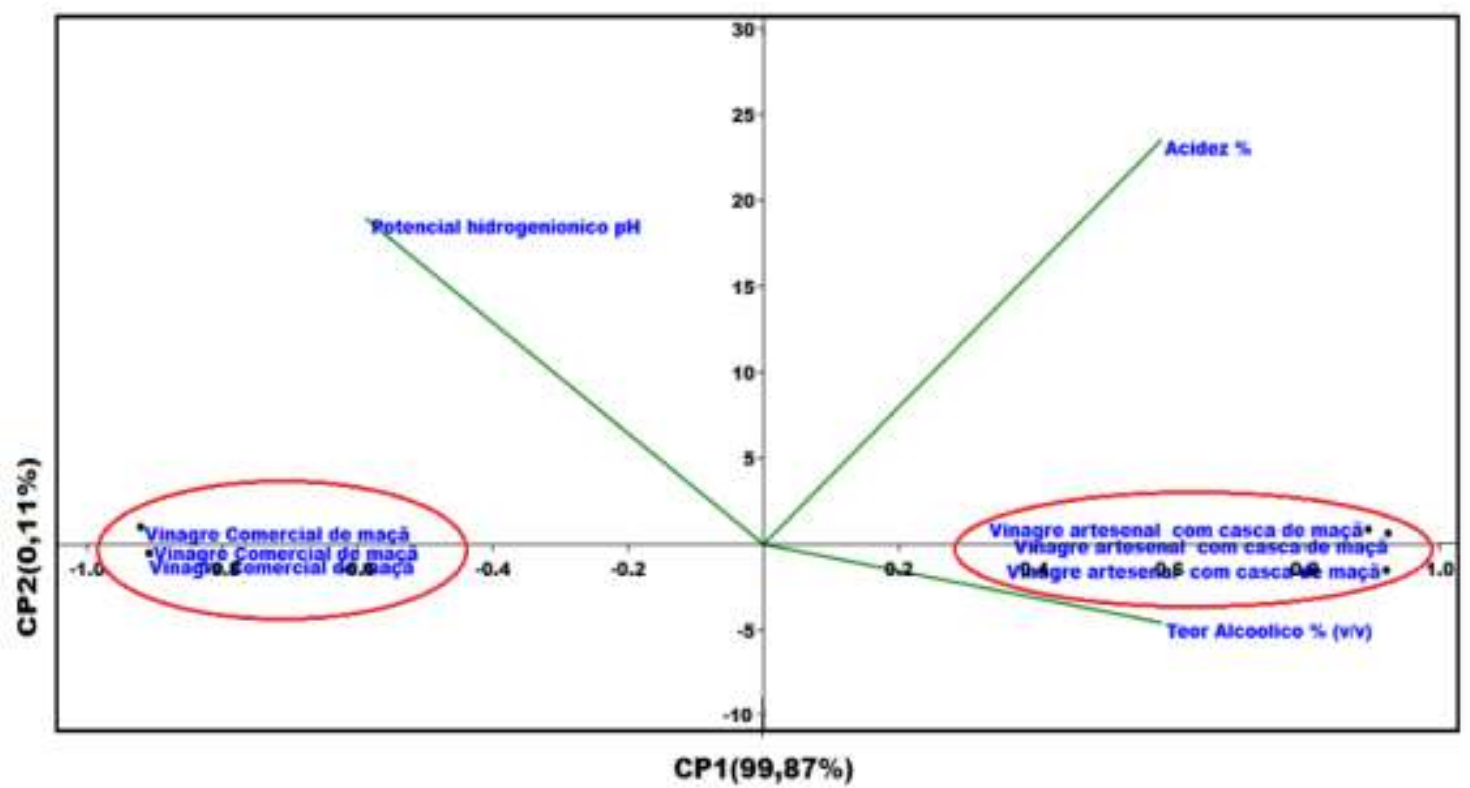

Fonte: Autores (2021).

A Figura 01 demostra a relação entre a componente principal CP1 versus a componente principal CP2, obtida a partir de um modelo com 99,98\% de variância total. Com base na Figura 6 é possível observar uma distinção entre o grupo do vinagre comercial (industrializado) e o grupo do vinagre fabricado com casca de maçã (artesanal). Observamos ainda que, o vinagre fabricado com casca de maçã pelo processo lento está relacionado com os maiores teores de acidez e teor alcoólico e o vinagre comercial produzido industrialmente pelo método rápido apresentou maior potencial hidrogeniônico pH.

\section{Conclusão}

As analises físico-químicas acidez volátil, $\mathrm{pH}$ e teor alcoólico, $\mathrm{pH}$ do vinagre fabricado com casca de maçã analisado apresentou diferenças inciativas em relação ao vinagre comercial produzido industrialmente. Essas diferenças não foram ao acaso e estão relacionadas ao processo de fabricação. O processo da fabricação do vinagre produzido com cascas de maçã apresentou facilidade de montagem e pouca quantidade de insumo para a produção do vinagre. O vinagre produzido com cascas da maçã em um reator produzido com garrafas PET, apresentou resultados obtidos nas análises físico-químicas da acidez e teor alcoólico de acordo com a Instrução Normativa nº 6, de 3 de abril de 2012 do Ministério da Agricultura, Pecuária e Abastecimento, com características físico-químicas semelhantes aos fermentados produzidos industrialmente e apto a ser comercializado e consumido como vinagres.

Considerando-se os resultados obtidos sugere-se que novos estudos sobre produção de vinagre com cascas de frutas sejam realizados para fomentar a geração de renda familiar e desenvolvimento econômico local. 


\section{Agradecimentos}

A Deus toda honra, glória e mérito. Ser Supremo Onisciente, Onipresente e Onipotente prior de toda ciência, sabedoria e poder que nos possibilita o livre arbítrio, conduzindo-nos à escolha pela ciência, provendo-nos de conhecimento.

\section{Referências}

Abrafrutas. Associação Brasileira dos Produtores Exportadores de Frutas e Derivados (2021). Pandemia reflete nos lucros de produtores de maçã em Palmas. < https://abrafrutas.org/2021/04/pandemia-reflete-nos-lucros-de-produtores-de-maca-em-palmas/>

Abdi, H. \& Williams, L. J. (2010). Principal component analysis. Wiley Interdisciplinary Reviews: Computational Statistics, 2(4), 433-459.< https://onlinelibrary.wiley.com/doi/epdf/10.1002/wics.101>

Aquarone, E. \& Zacanaro, J. O. (1983). Vinagres. In: AQUARONE, E.; LIMA, U. A.; BORZANI, W. (Coord.). Alimentos e bebidas produzidos por fermentação: biotecnologia. São Paulo: E. Blücher, 1983. v. 5, p. 104- 122.

Assis, J. P., Sousa, R. P. de, \& Linhares, P. C. F. (2020). Testes de hipóteses estatísticas. Mossoró: EdUFERSA 182 p. ISBN: 978-65-87108-06-3.

Betinelli, K. S., Martin M. S. de, Argenta, L., C., Amarante, C., V., T. do, \& Denardi, F. (2017). Estádio de maturação para colheita de maçãs 'scs426 venice'. Agropecuária Catarinense, Florianópolis, v.30, n.2, p.57-62.

Bruna-Maynou, F. J., Castro, R., Rodríguez-Dodero, M. C., G. Barroso, C., \& Durán-Guerrero, E. (2020). Flavored Sherry vinegar with citric notes: Characterization and effect of ultrasound in the maceration of orange peels. Food Research International, 133, 109165. doi:10.1016/j.foodres.2020.109165

Budak, N.H., Aykin, E., Seydim, A.C., Greene, A.K. and Guzel-Seydim, Z.B. (2014) Functional Properties of Vinegar. Journal of Food Science, 79, R757R764. https://doi.org/10.1111/1750-3841.12434

Bueno, M. P., Silva, A. C., Nunes, A. L. de P. F., Sardinha, A. C., Lima, P. T. dos S., Silva, J. F. (2021). Análise da comercialização da cadeia produtiva da maçã brasileira: produção, importação e exportação no período 2015 a 2019. Brazilian Journal of Development, Curitiba, v.7, n.4, p. 34061-34078 apr. DOI: $10.34117 / \mathrm{bjdv} 7 \mathrm{n} 4-048$

Ezemba, A.S., Osuala, O.J., Orji, M.U., Ezemba, C.C., \& Anaukwu, C. (2021). Production and Comparative Physicochemical Analysis of Vinegar from Locally Grown Fruits in Nigeria and Industrial Produced Vinegar. American Journal of Microbiological Research, 9(1), 25-33. DOI:10.12691/ajmr-9-1-4

Ferreira, D. F. (2019). Sisvar: A computer analysis system to fixed effects split plot type designs. Revista Brasileira de Biometria, [S.1.], v. 37, n. 4, p. 529535. DOI: https://doi.org/10.28951/rbb.v37i4.450.

Ferreira, J. C. \& Patino, C. M. (2015). What does the p value really mean? Jornal Brasileiro de Pneumologia:441(5):485 485. https://doi.org/10.1590/S180637132015000000215

FAO. (2019). Food and Agriculture Organization. The State of Food and Agriculture: Moving Fordward on Food Loss and Waste Reduction

Fraga, A. B., Silva, F. de L., Hongyu, K., Santos D. da S., Murphy, T. W. \& Lopes, F. B (2015). Multivariate analysis to evaluate genetic groups and productiontraits of crossbred Holstein $\times$ Zebu cows. Trop Anim Health Prod.p. 1-6.

García, G, I Santos, D. I. M., Ot, J. C., Hornero, J. J. E. \& Venceslada, J. L. B. (2009). Vinegar engineering. In: Solieri, L., Giudici, P. (Ed.) Vinegars of the World. 97-120.

Hasan, A. N., Antony, U., Bala, G.V., Prabha, D.T., Kavya, C. \& Malik, A. F. (2021). Study on Production Vinegar from Apple. IOP Conf. Series: Earth and Environmental Science 761 (2021) 012125. doi:10.1088/1755-1315/761/1/012125

Hommer, O. Harper, D.A.T. \& Ryan, P.D. (2001). PAST: Paleontological statistics software package for education and data analysis. Paleontol. Elet. 4(1):9.

Hopkins, W. G. (2016). A new view of statistics. Middlesbrough: Internet Society for SportScience.

IAL (2008). Instituto Adolfo Lutz. Métodos físico-químicos para análise de alimentos. IV ed. (1ª Edição digital) São Paulo.1020p

Kang, M; Há, J. H. \& Lee, Y. (2020). Propriedades físico-químicas, atividades antioxidantes e características sensoriais de vinagres comerciais de gape durante o armazenamento a longo prazo. Food Sci. Technol (Campinas) 40 (4). DOI: https://doi.org/10.1590/fst.25119

Launholt, T.L., Kristiansen, C.B. \& Hjorth, P. Safety and side effects of apple vinegar intake and its effect on metabolic parameters and body weight: A systematic review. Eur. J. Nutr. 2020, 59, 2273-2289. DOI: 10.1007/s00394-020-02214-3

Jingjing, L., Xie, J., Hou, L, Zhao, M, Zhao, J., Cheng, J. , Wang, S. \& Sun, B. G. (2016). Aroma Constituents in Shanxi Aged Vinegar before and after Aging. Journal of Agric Food Chemistry 64(40):7597-7605. DOI: https://doi.org/10.1021/acs.jafc.6b03019

Liu, Q., Li, X., Sun, C., Wang, Q., Yao, H , Yang, W., Zheng, Z., Zhi , Jiang, S \& Wu, X. (2019). Effects of mixed cultures of Candida tropicalis and aromatizing yeast in alcoholic fermentation on the quality of apple vinegar. 3 Biotech, 9(4), 128. https://doi.org/10.1007/s13205-019-1662-3 
Quintana, L.L.M.; Castro, R. \& Guerrero, D. E. (2021). Biotechnological Processes in Fruit Vinegar Production. Foods 2021, 10, 945. https://doi.org/10.3390/foods 10050945 .

Mahamuni, T. \& Gilda. S.S. Manufacturing of Apple cider vinegar. International Journal of Research and Analytical Reviews (IJRAR). R April 2020, Volume 7, Issue 2 .

Marques, F. P. P., Spinosa, W., Fernandes, K. F., Castro, C. F. de S. \& Caliari, M. (2008). Padrões de identidade e qualidade de fermentados acéticos comerciais de frutas e vegetais. Ciênc. Tecnol. Aliment., Campinas, v. 30, supl. 1, p. 119 126. DOI: https://doi.org/10.1590/S0101-20612010000500019.

Moore, D. S., Notz, W. I \& Flinger, M. A. (2017). A estatística básica e sua prática. Editora : LTC; $7^{a}$ edição. 659 p.

Pereira A. S., Shitsuka, D. M., Parreira, F. J., \& Shitsuka, R. (2018). Metodologia da pesquisa científica. UFSM. https://repositorio.ufsm.br/bitstream/handle/ /15824/Lic_Computacao_Metodologia-Pesquisa-Cientifica.pdf?sequence=1

Perestrelo, R., Silva, C. L., Silva, P. \& Câmara, J. S. (2018). Establishment of the Volatile Signature of Wine-Based Aromatic Vinegars Subjected to Maceration. Molecules. 23(2), 499. DOI: https://doi.org/10.3390/molecules23020499

Raspor, P., \& Goranovič, D. (2008). Biotechnological applications of acetic acid bacteria. Critical Reviews in Biotechnology, 28:101-124. DOI: $10.1080 / 07388550802046749$

Rizzon, L. A. \& Miele, A. (1998). Características analíticas de vinagres comerciais de vinhos brasileiros. Brazilian Journal of Food Technology, Campinas, v. 1, n. 1.2, p. 25-31.

Romero, C. D. , Torre, A. H. \& Artiles, A. A. (1993). Caracterization fisicoquimica de diferentes tipos de vinagres: determination de algunos parametros de naturaleza volátil. Alimentaria, Madrid, p. 105-107.

Santos, G. C. , Júnior, U. G. da S., Neto, J. A. da F., Filho, E. V. de C. (2008). Método alternativo de produção de vinagre com reaproveitamento de cascas de frutas. Revista Principia.n.16, p. 62-67. DOI:http://dx.doi.org/10.18265/1517-03062015v1n16p62-67

SEBRAE. (2020). Serviço Brasileiro de Apoio às Micro e Pequenas Empresas SEBRAE. (2020). O Cultivo $e$ o Mercado da maçã. < https://www.sebrae.com.br/sites/PortalSebrae/sbrt/maca-peruana,0800ffcc7ffa0710VgnVCM1000004c00210aRCRD>

Song, J., Zhang, J. H., Kang, S. J., Zhang, H. Y., Yuan, J., Zeng, C. Z., Zhang, F., \& Huang, Y. L. (2019). Analysis of microbial diversity in apple vinegar fermentation process through 16s rDNA sequencing. Food science \& nutrition, 7(4), 1230-1238. https://doi.org/10.1002/fsn3.944

Tessaro, D., Larsen, A. C., Dallago, R. C., Damasceno, S. G., Sene, L., \& Coelho, S. R. M. (2010). Avaliação das fermentações alcoólica e acética para produção de vinagre a partir de suco de laranja. Acta Scientiarum. Technology Maringá, v. 32, n. 2 p. 201-205. DOI: 10.4025/actascitechnol.v32i2.4275

Umaru, F. F., Esedafe, W. K., Obidah, J. S., Akinwotu, O., \& Danba, E. (2015). Production of vinegar from pineapple peel wine using Acetobacter species. 3rd International Conference on Biological Chemical and Environmental Sciences, Kuala Lumpur (Malaysia) 1-3.

Viana, R. O, Guedes, K. T. M., Braga, R. A, Jr, Dias, D. R. \& Schwan, R. F. (2017). Fermentation process for production of apple-based kefir vinegar: microbiological, chemical and sensory analysis. Brazilian Journal of Microbiology $48592-601$

Viroli, S. L. M., Biase, R. S., \& Rodrigues. F. M. (2019, 21 a 27 de julho). Production and characterization of handmade vinegar produced with apple peels. [Apresentação de Trabalho]. Anais da 71ª Reunião Anual Sociedade Brasileira para o Progresso da Ciência. UFMT. Campo Grande -MT.

White, J. (1971). Vinegar quality: legal and commercial standards. Process Biochemistry, London, p. 21 - 25.

Wang Z, Li T, Liu F, Zhang C, Ma H, Wang L \& Zhao S. (2017). Effects of ultrasonic treatment on the maturation of Zhenjiang vinegar. Ultrason Sonochem 39:272-280. https:// doi.org/10.1016/j.ultsonch.2017.04.020

Wu X, Yao H, Cao X, Liu Q, Cao L, Mu D, Luo S, Zheng Z, Jiang S \& Li X. (2017). Production of vinegar from purple sweet potato in a liquid fermentation process and investigation of its antioxidant activity. 3 Biotech.7 (5), 308. https://doi.org/10.1007/s13205-017-0939-7

Xie X, Zheng Y, Liu X, Cheng C, Zhang X, Xia T, Yu S, \& Wang M. (2017). Antioxidant activity of chinese shanxi aged vinegar and its correlation with polyphenols and flavonoids during the brewing process. J Food Sci 82(10):2479-2486. https://doi. org/10.1111/1750-3841.13914 